\title{
Liquid Biopsy in Metastasized Breast Cancer as Basis for Treatment Decisions
}

\author{
Natalia Krawczyk ${ }^{a}$ Tanja Fehm ${ }^{a}$ Malgorzata Banys-Paluchowski ${ }^{a}$ Wolfgang Janni ${ }^{b}$ \\ Amelie Schramm ${ }^{\text {b }}$ \\ a Department of Obstetrics and Gynecology, University of Düsseldorf, Düsseldorf, Germany; \\ ${ }^{b}$ Department of Obstetrics and Gynecology, University of UIm, UIm, Germany
}

\section{Keywords}

Circulating tumor cells - Circulating tumor DNA .

Metastatic breast cancer - Liquid biopsy

\section{Summary}

According to current guidelines, the additional biopsy of breast cancer metastases to analyze the receptor status for phenotype assessment is recommended. However, due to clinical difficulties in performing biopsies of metastatic lesions, the phenotype of the primary tumor most often determines the treatment decisions in metastatic breast cancer. Liquid biopsy allows the analysis of several circulating biomarkers like circulating tumor cells (CTCs) or circulating tumor DNA (ctDNA) in peripheral blood samples of cancer patients. Thus, it is an elegant and easily practicable technique that delivers information on the current disease status. Determination of the CTC phenotype regarding the hormone receptor and human epidermal growth factor receptor 2 (HER2) status might replace additional tissue biopsy for planning further therapy strategies. Liquid biopsy is a crucial step towards a more individualized cancer therapy. In contrast to the conventional concept of tissue biopsy, it offers an easy, less invasive acquisition of biomaterial. In addition, it allows multiple repetitions and real-time monitoring of metastasized disease in the clinical routine. However, the clinical utility of liquid biopsy still needs to be evaluated.

(c) 2016 S. Karger GmbH, Freiburg

\section{Background}

Metastatic breast cancer (MBC) is still a challenge for clinicians as it is the cause of death in about $20 \%$ of patients initially diagnosed with localized disease [1]. As in the curative setting, treatment decisions in MBC are based on the hormone receptor (HR) and/or human epidermal growth factor receptor 2 (HER2) status. Based on the knowledge that the expression profile of breast cancer may change in the course of disease, national and international guidelines advise an additional biopsy of metastatic lesions for further assessment of the breast cancer phenotype in $\operatorname{MBC}[2,3]$. However, due to limited tissue accessibility and invasiveness of the procedure, repeated sampling of metastases is often not feasible and the current treatment decisions in $\mathrm{MBC}$ are still mostly based on the biological characteristics of the primary tumor. Moreover, since $\mathrm{MBC}$ represents a heterogeneous disease, reevaluation of the tumor characteristics founded on the biopsy of 1 metastatic lesion may not sufficiently reflect the tumor burden $[4,5]$.

In this context, a simple and noninvasive blood analysis for solvent biomarkers like circulating tumor cells (CTCs) or free circulating tumor DNA (ctDNA) as a 'liquid biopsy' may represent an attractive alternative allowing the real-time monitoring of disease progression and therapy response.

\section{CTCs as a Prognostic and Predictive Tool in MBC}

CTCs can be detected in $40-80 \%$ of patients with MBC. Cristofanilli et al. [6] in 2004 were the first to report that CTC counts above the cut-off value of 5 cells per $7.5 \mathrm{ml}$ of blood indicate an unfavorable clinical outcome. The prognostic role of CTCs in MBC patients has been further demonstrated by several studies [7-13]. A recent pooled analysis on 1,944 $\mathrm{MBC}$ patients confirmed the influ- 
ence of CTC detection on progression-free survival (PFS) and overall survival (OS) with the highest level of evidence [14].

Beyond the prognostic impact of CTC detection in MBC patients, dynamic changes in CTC counts during therapy have been reported to reflect treatment response: In the study by Hayes et al. [9], a decrease in CTC levels under the cut-off value of 5 cells predicted better PFS and OS. Moreover, therapy response assessed by evaluation of the CTC dynamics might be more suitable for therapy monitoring than standard radiological imaging [8]. In a prospective multicenter trial by Budd et al. [8], persistently high levels of CTCs predicted worse clinical outcome despite radiological therapy response.

Additionally, several studies have shown that the phenotypes and genotypes of the primary tumor, the metastatic lesion, and CTCs often differ, especially with regard to the HR and HER2 status [1519]. Since CTCs in MBC possibly most adequately represent the current dominant clone of tumor cells, their expression profile may predict therapeutic response [20]. It has been demonstrated in small experimental trials that targeted therapy guided by the CTC phenotype is able to eliminate persistent tumor cells from the blood and/or bone marrow of breast cancer patients [21-23]. The clinical significance of the CTC phenotype (in particular, the HER2 status) for guiding therapeutic decisions and evaluating treatment response is being investigated within the DETECT studies. Furthermore, recent research reported the possibility to provide an analysis of CTCs on the DNA, RNA, and protein level including next-generation sequencing (NGS) [24]. CTC characterization on the molecular level might help to identify resistance mechanisms of tumor cells: an important step for the optimization of systemic treatment [20]. In this context, one of the main goals of the recently initiated PRAEGNANT trial (NCT02338167) is to correlate liquid biopsy-based tumor assessments with actual tumor characteristics in order to facilitate comprehensive tumor profiling and evaluate new bloodbased prognostic and predictive biomarkers in MBC patients [25].

\section{Limitations and Challenges}

Since CTCs are a rare event, despite easy achievement of the blood sample, their detection remains challenging, requiring complex enrichment procedures [26]. Thus, the use of liquid biopsy for the assessment of the breast cancer pheno- or genotype is limited to patients with relevant CTC counts. Moreover, most of the CTC detection methods are based on their epithelial character, missing the cells that underwent epithelial-mesenchymal transition (EMT). In this process, assumed to be responsible for cancer resistance to therapy, CTCs lose their epithelial features and express mesenchymal or stem cell markers $[27,28]$. Finally, the impact of CTCdriven clinical decisions still needs to be evaluated.

\section{ctDNA as a Biomarker in MBC}

ctDNA consists in degraded DNA fragments released into the blood circulation from tumor cells undergoing necrosis or apopto- sis [29]. These small DNA fragments have to be differentiated from other cell-free DNA (cfDNA) in peripheral blood (PB) based on the identification of tumor-specific mutations. Detection and genomic analysis of ctDNA, including NGS, may represent a promising noninvasive tool for the characterization of tumor material circulating in the $\mathrm{PB}$ and for monitoring the efficacy of anticancer treatment.

Several studies till date have demonstrated that ctDNA can be detected in the $\mathrm{PB}$ of early-stage and $\mathrm{MBC}$ patients [30-32]. In the study by Bettegowda et al. [30], ctDNA was detected in $82 \%$ of the patients with metastatic malignancies and in 55\% of the patients with localized tumors, also in breast cancer. Rothe et al. [32] demonstrated in their pilot trial using NGS that ctDNA can serve as a biomarker for cancer monitoring and as a serious alternative to metastatic biopsy; in 13/17 (76\%) patients examination of plasma samples and metastatic tissue showed concordant results, whereas in $2 / 17(12 \%)$ patients ctDNA analysis revealed additional information. Moreover, several groups have shown that the load of ctDNA adequately reflects the tumor burden and that high levels of ctDNA are associated with poor prognosis [29, 31, 33-35]. In the study by Dawson et al. [31], ctDNA has been detected in 29/30 (97\%) MBC patients, showing higher sensitivity and higher correlation with the tumor burden than cancer antigen $(\mathrm{Ca})$ 15-3 or CTCs. In contrast, in their study investigating the dynamic range of ctDNA in MBC patients, Heidary et al. [36] demonstrated unexpectedly low frequencies of ctDNA in patients with tumor progression, which neither reflected the tumor burden nor the dynamics of the disease. Moreover, in the recently published trial by Madic et al. [37] analyzing TP53 mutation in primary tumors and corresponding plasma samples of triple-negative MBC patients, ctDNA was detected in $81 \%$ of the patients with TP53-positive tumors whereas only $52 \%$ of these patients had $\geq 5$ CTCs in the PB. However, the ctDNA levels have shown no prognostic impact on the time to progression (TTP) or OS whereas CTCs counts were associated with a shorter OS $(\mathrm{p}=0.04)$.

Beyond ctDNA detection in the plasma of cancer patients in order to monitor disease dynamics, some groups were able to trace ctDNA mutations relevant to anticancer treatment resistance [3840]. Murtaza et al. [38] demonstrated in their study on 6 patients with advanced ovarian, breast and lung cancers that a high incidence of specific ctDNA alterations is associated with acquired drug resistance: A truncating mutation in the gene coding for mediator complex subunit 1 (MED1) was found in an MBC patient with progressive disease following treatment with tamoxifen and trastuzumab, and a splicing mutation in the growth arrest-specific 6 (GAS6) gene was identified in the same MBC patient following subsequent treatment with lapatinib. Sefrioui et al. [39] demonstrated that the mutation in the estrogen receptor 1 (ESR1) gene that is responsible for resistance to endocrine therapy in breast cancer patients can be traced in ctDNA and possibly predicts disease progression.

In summary, ctDNA analysis has a great potential in monitoring disease dynamics and treatment response in MBC. However, the major challenge of this method is the low sensitivity, specificity, 
Table 1. Potentials and limitations of liquid biopsy

\begin{tabular}{|c|c|c|}
\hline \multirow[t]{2}{*}{ Potentials of liquid biopsy } & \multicolumn{2}{|c|}{ Limitations of liquid biopsy } \\
\hline & CTCs & ctDNA \\
\hline Noninvasive and simple tissue assessment & rare event & $\begin{array}{l}\text { necrotic or apoptotic } \\
\text { tumor cells }\end{array}$ \\
\hline Easy repetition & $\begin{array}{l}\text { epithelial cell-based } \\
\text { detection methods }\end{array}$ & $\begin{array}{l}\text { no standard detection } \\
\text { method }\end{array}$ \\
\hline Early detection of minimal residual disease & \multicolumn{2}{|c|}{ clinical validation required } \\
\hline $\begin{array}{l}\text { Blood-based tumor profiling on DNA, RNA, } \\
\text { and protein levels }\end{array}$ & \multicolumn{2}{|c|}{ potential selection of irrelevant subclones } \\
\hline Real-time disease monitoring & \multicolumn{2}{|c|}{$\begin{array}{l}\text { discordance between expression profiles of clinically } \\
\text { predominant metastases and biomaterial in liquid biops }\end{array}$} \\
\hline Prediction of treatment response & \multicolumn{2}{|c|}{ financial effort for analysis (e.g. NGS) } \\
\hline
\end{tabular}

$\mathrm{CTC}=$ Circulating tumor cell, ctDNA = circulating tumor DNA, NGS = next-generation sequencing. and lack of standardization of existing approaches, which may lead to discordant results [41]. Moreover, the question why ctDNA, mostly released from dying tumor cells, should carry information crucial for understanding resistant tumor cell populations still needs to be answered [20]. The potentials and limitations of liquid biopsy are summarized in table 1 .

\section{Clinical Investigations Regarding the Utility of Liquid Biopsy for Treatment Decisions in MBC}

While the clinical relevance of ctDNA diagnostics remains to be clarified, CTC detection has proven its prognostic significance in large clinical trials $[7,42]$. Since CTC positivity predicts worse clinical outcome and changes in CTC counts seem to reflect therapy response, the question has been raised whether MBC patients can benefit from treatment decisions based on the CTC dynamics. The first study initiated in order to clarify this issue is the Southwest Oncology Group (SWOG) S0500 trial (NCT00382018). In this phase III randomized trial, patients with advanced breast cancer and persistently high CTC counts after 3 weeks of first-line chemotherapy ( $\geq 5 \mathrm{CTCs} / 7.5 \mathrm{ml}$ of blood) were randomized between switching to an alternative treatment and continuing current therapy until the clinical evidence of disease progression [43]. First results of this trial were presented at the San Antonio Breast Cancer Symposium 2013 and showed no improvement in OS of patients who switched to a new treatment regime based on CTC persistence. However, the study confirmed the strong prognostic impact of CTCs: The median OS reached 35 months in patients with initially low CTC counts, 23 months in patients with CTC decrease under the therapy, and 13 months in patients with persistently high CTC counts. Thus, patients with CTC persistence under the cytotoxic treatment might represent a chemoresistant population that requires alternative treatment approaches [43]. Another, currently ongoing trial evaluating whether treatment decisions in $\mathrm{MBC}$ can be guided by CTC is the CirCe01 study by the Institut Curie, France (NCT01349842). In this multicenter, randomized, phase III trial, treatment response in CTC-positive MBC patients progres- sive after 2 lines of chemotherapy is being evaluated by conventional clinical and radiological assessment versus by determination of CTCs. Patients without significant CTC decrease after the first cycle of a new chemotherapy will be switched to an alternative regime, which will also be evaluated by CTCs after the first cycle. Both studies attempt to demonstrate that patients with persistently high levels of CTCs under cytotoxic therapy should be switched from this treatment at an early time point in order to avoid inefficient and toxic chemotherapies. First results of CirCe01 are expected in 2018 [44]. The question whether the choice between chemotherapy and endocrine therapy in HR-positive MBC patients might be driven by CTC counts has been addressed by the STIC-CTC trial of the Institut Curie, France (NCT01710605). In the standard arm of this randomized, phase III study the treatment decision will be made by clinicians, whereas in the CTC arm the treatment decision will be driven by CTC counts: endocrine therapy if CTC count $<5$ CTCs $/ 7.5 \mathrm{ml} \mathrm{PB}$ or chemotherapy if CTC count $\geq 5$ CTCs/ $7.5 \mathrm{ml} \mathrm{PB}$.

The worldwide largest trial design for liquid biopsy using CTCs in MBC is the DETECT study concept. Treatment decisions based on the presence and phenotype of CTCs are investigated in this multicenter study. Women with HER2-negative MBC are screened for CTCs using the CELLSEARCH system (Janssen Diagnostics). In patients with at least 1 CTC, the HER2 status of each CTC is determined. Patients with 1 or more HER2-positive CTCs are included in the DETECT III trial (NCT01619111); women with only HER2-negative CTCs are eligible for DETECT IV (NCT02035813). DETECT V/CHEVENDO (NCT02344472), recently started in September 2015, completes the DETECT study program with a clinical trial for HER2-positive MBC patients.

In DETECT III, patients are randomized 1:1 to standard therapy plus or minus additional treatment with lapatinib. The standard endocrine or standard chemotherapy is chosen according to the physician's choice. DETECT IV offers 2 different treatment cohorts, with everolimus and eribulin as study medication. Postmenopausal women with HR-positive tumors are treated with everolimus plus endocrine therapy (anastrozol, letrozol, tamoxifen, or exemestane). Patients with HR-positive tumors and the need for 
Table 2. Current studies on CTC-based treatment decisions in $\mathrm{MBC}$

\begin{tabular}{|c|c|c|c|c|c|}
\hline Study & Status & $\begin{array}{l}\text { Estimated } \\
\text { enrollment }\end{array}$ & Condition & Intervention & $\begin{array}{l}\text { Primary } \\
\text { endpoint }\end{array}$ \\
\hline $\begin{array}{l}\text { SWOG S0500, } \\
\text { NCT00382018 } \\
\quad \text { (phase III) }\end{array}$ & $\begin{array}{l}\text { active, not } \\
\text { recruiting }\end{array}$ & 561 & $\begin{array}{l}\text { CT-resistant, CTC- } \\
\text { positive } \mathrm{MBC}\end{array}$ & $\begin{array}{l}\text { treatment choice according to } \\
\text { clinical and radiological criteria } \\
\text { vs. CTC-driven treatment choice }\end{array}$ & OS \\
\hline $\begin{array}{l}\text { CirCe01, } \\
\quad \text { NCT01349842 } \\
\quad \text { (phase III) }\end{array}$ & recruiting & 568 & $\begin{array}{l}\text { CT-resistant, CTC- } \\
\text { positive } \mathrm{MBC}\end{array}$ & $\begin{array}{l}\text { treatment choice according to } \\
\text { clinical and radiological criteria } \\
\text { vs. CTC-driven treatment choice }\end{array}$ & OS \\
\hline $\begin{array}{l}\text { STIC-CTC, } \\
\quad \text { NCT01710605 } \\
\quad \text { (phase III) }\end{array}$ & recruiting & 1,000 & $\mathrm{HR}+/ \mathrm{HER} 2-\mathrm{MBC}$ & $\begin{array}{l}\text { clinicians choice vs. CTC-driven } \\
\text { choice between CT and ET }\end{array}$ & PFS \\
\hline $\begin{array}{l}\text { DETECT III, } \\
\text { NCT01619111 } \\
\text { (phase III) }\end{array}$ & recruiting & 120 & $\begin{array}{l}\text { HER2- MBC, } \\
\text { HER2+ CTCs }\end{array}$ & standard therapy \pm lapatinib & $\begin{array}{l}\text { CTC } \\
\text { clearance }\end{array}$ \\
\hline $\begin{array}{l}\text { DETECT IV, } \\
\text { NCT02035813 } \\
\text { (phase II) }\end{array}$ & recruiting & 520 & $\begin{array}{l}\text { HER2- MBC, } \\
\text { HER2- CTCs }\end{array}$ & $\begin{array}{l}\mathrm{ET}+\text { everolimus (DIVa) or } \\
\text { eribulin (DIVb) }\end{array}$ & PFS \\
\hline $\begin{array}{l}\text { NCT01975142 } \\
\text { (phase II) }\end{array}$ & recruiting & 480 & $\begin{array}{l}\text { HER2- MBC, } \\
\text { HER2+ CTCs }\end{array}$ & T-DM1 & $\begin{array}{l}\text { tumor } \\
\text { response rate }\end{array}$ \\
\hline
\end{tabular}

more aggressive treatment or patients with triple-negative tumors are included in the eribulin cohort. Patients with HR-positive, HER2-positive MBC are randomized 1:1 in DETECT V/CHEVENDO to a dual HER2-targeted therapy with pertuzumab and trastuzumab either in combination with chemotherapy (docetaxel, paclitaxel, capecitabine, vinorelbin) or endocrine therapy (fulvestrant, tamoxifen, letrozol, anastrozol, or exemestane).

In DETECT III and DETECT IV, the presence of CTCs is mandatory for study inclusion and changes in CTC counts during therapy are evaluated as study endpoints. As another objective, e.g., the benefit of an additional anti-HER2-targeted therapy in women with HER2-negative MBC and HER2-positive CTCs is analyzed in DETECT III. Efficacy of the study treatment is evaluated in DETECT III, DETECT IV, and DETECT V/CHEVENDO. In contrast to previous evaluations of safety and tolerability, DETECT V/CHEVENDO emphasizes the importance of quality of life in MBC patients. A modified adverse event score and the 'quality-adjusted time without symptoms and toxicity' (Q-TWiST) method is used for assessing the value of life time.

The accompanying translational research projects try to generate additional knowledge of CTCs, their tumor biology and predictive value for cancer therapy, using methods like single-cell analysis, SNaPshot technology, and NGS.

In the DETECT III and DETECT IV trials, mutations of the phosphatidylinositol 3-kinase (PI3K)/Akt signaling pathway and the mutation status of ESR1 and the androgen receptor are analyzed. Solvent markers like tissue inhibitor of metalloproteinase 1 (TIMP-1) and carboanhydrase 9 (CA IX) or various circulating microRNAs (miRNA-125a/b, miRNA-18a/b) are also part of translational research projects. In addition, the roles of transcription fac- tors in EMT and the value of DNA damage and repair markers for the prediction of treatment response to eribulin are assessed.

The value of CTC changes during therapy, determined by repeated sampling during therapy and interpretation of their dynamics, is assessed within the translational research program of all DETECT studies. Furthermore, the identification of potential targets for more individualized treatment options might improve the utility of CTCs in clinical routine. Especially in the DETECT V/CHEVENDO trial, research projects are mainly focused on CTCs and their use for the prediction of treatment response. Current studies on CTC-based treatment decisions in MBC are summarized in table 2 .

\section{Conclusion}

Liquid biopsy in $\mathrm{MBC}$ represents an innovative technique for sampling circulating biomarkers. Information based on the detection and analysis of CTCs, ctDNA, and additional markers may provide crucial information for appropriate breast cancer treatment and individualized targeted therapy. Risk assessment and monitoring of treatment responses allow personalized therapy strategies. Further translational research is needed to obtain more detailed knowledge of circulating biomarkers and their clinical implications for daily routine.

\section{Disclosure Statement}

The authors declare no conflicts of interest. 


\section{References}

1 Weigelt B, Peterse JL, van 't Veer LJ: Breast cancer metastasis: markers and models. Nat Rev Cancer 2005;5: 591-602.

2 Amir E, Clemons M, Purdie CA, Miller N, Quinlan P, Geddie W, Coleman RE, Freedman OC, Jordan LB, Thompson AM: Tissue confirmation of disease recurrence in breast cancer patients: pooled analysis of multi-centre, multi-disciplinary prospective studies. Cancer Treat Rev 2012;38:708-714.

3 Pantel K, Brakenhoff RH, Brandt B: Detection, clinical relevance and specific biological properties of disseminating tumour cells. Nat Rev Cancer 2008;8:329-340.

4 Gerlinger M, Rowan AJ, Horswell S, Larkin J, Endesfelder D, Gronroos E, Martinez P, Matthews N, Stewart A, Tarpey $\mathrm{P}$, et al.: Intratumor heterogeneity and branched evolution revealed by multiregion sequencing. N Engl J Med 2012;366:883-892.

5 Wang Y, Waters J, Leung ML, Unruh A, Roh W, Shi X, Chen K, Scheet P, Vattathil S, Liang H, et al.: Clonal evolution in breast cancer revealed by single nucleus genome sequencing. Nature 2014;512:155-160.

-6 Cristofanilli M, Hayes DF, Budd GT, Ellis MJ, Stopeck A, Reuben JM, Doyle GV, Matera J, Allard WJ, Miller $\mathrm{MC}$, et al.: Circulating tumor cells: a novel prognostic factor for newly diagnosed metastatic breast cancer. J Clin Oncol 2005;23:1420-1430.

7 Cristofanilli M, Budd GT, Ellis MJ, Stopeck A, Matera J, Miller MC, Reuben JM, Doyle GV, Allard WJ, Terstappen LW, Hayes DF: Circulating tumor cells, disease progression, and survival in metastatic breast cancer. N Engl J Med 2004;351:781-791.

8 Budd GT, Cristofanilli M, Ellis MJ, Stopeck A, Borden E, Miller MC, Matera J, Repollet M, Doyle GV, Terstappen LW, Hayes DF: Circulating tumor cells versus imaging - predicting overall survival in metastatic breast cancer. Clin Cancer Res 2006;12:6403-6409.

9 Hayes DF, Cristofanilli M, Budd GT, Ellis MJ, Stopeck A, Miller MC, Matera J, Allard WJ, Doyle GV, Terstappen LW: Circulating tumor cells at each follow-up time point during therapy of metastatic breast cancer patients predict progression-free and overall survival. Clin Cancer Res 2006;12:4218-4224.

10 Giuliano M, Giordano A, Jackson S, Hess KR, De Giorgi U, Mego M, Handy BC, Ueno NT, Alvarez RH, De Laurentiis M, et al.: Circulating tumor cells as prognostic and predictive markers in metastatic breast cancer patients receiving first-line systemic treatment. Breast Cancer Res 2011;13:R67.

-11 Pierga JY, Bidard FC, Mathiot C, Brain E, Delaloge S, Giachetti S, de Cremoux P, Salmon R, Vincent-Salomon A, Marty M: Circulating tumor cell detection predicts early metastatic relapse after neoadjuvant chemotherapy in large operable and locally advanced breast cancer in a phase II randomized trial. Clin Cancer Res 2008;14:7004-7010.

12 Giordano A, Giuliano M, De Laurentiis M, Arpino G, Jackson S, Handy BC, Ueno NT, Andreopoulou E, Alvarez RH, Valero V, et al.: Circulating tumor cells in immunohistochemical subtypes of metastatic breast cancer: lack of prediction in HER2-positive disease treated with targeted therapy. Ann Oncol 2012;23:1144-1150.

$\checkmark 13$ Wallwiener M, Hartkopf AD, Baccelli I, Riethdorf S, Schott S, Pantel K, Marme F, Sohn C, Trumpp A, Rack $\mathrm{B}$, et al.: The prognostic impact of circulating tumor cells in subtypes of metastatic breast cancer. Breast Cancer Res Treat 2013;137:503-510.

14 Bidard FC, Peeters DJ, Fehm T, Nole F, Gisbert-Criado R, Mavroudis D, Grisanti S, Generali D, Garcia-Saenz JA, Stebbing J, et al.: Clinical validity of circulating tumour cells in patients with metastatic breast cancer: a pooled analysis of individual patient data. Lancet Oncol 2014;15:406-414.
5 Kalinsky K, Mayer JA, Xu X, Pham T, Wong KL, Villarin E, Pircher TJ, Brown M, Maurer MA, Bischoff FZ: Correlation of hormone receptor status between circulating tumor cells, primary tumor, and metastasis in breast cancer patients. Clin Transl Oncol 2015;17:539-546.

16 Babayan A, Hannemann J, Spotter J, Muller V, Pantel K, Joosse SA: Heterogeneity of estrogen receptor expression in circulating tumor cells from metastatic breast cancer patients. PLoS One 2013;8:e75038.

17 Pestrin M, Bessi S, Galardi F, Truglia M, Biggeri A, Biagioni C, Cappadona S, Biganzoli L, Giannini A, Di Leo A: Correlation of HER2 status between primary tumors and corresponding circulating tumor cells in advanced breast cancer patients. Breast Cancer Res Treat 2009;118:523-530.

18 Wallwiener M, Hartkopf AD, Riethdorf S, Nees J, Sprick MR, Schonfisch B, Taran FA, Heil J, Sohn C, Pantel K, et al.: The impact of HER2 phenotype of circulating tumor cells in metastatic breast cancer: a retrospective study in 107 patients. BMC Cancer 2015;15:403.

19 Fehm T, Muller V, Aktas B, Janni W, Schneeweiss A, Stickeler E, Lattrich C, Lohberg CR, Solomayer E, Rack B, et al.: HER2 status of circulating tumor cells in patients with metastatic breast cancer: a prospective, multicenter trial. Breast Cancer Res Treat 2010;124:403-412.

20 Pantel K, Alix-Panabieres C: Real-time liquid biopsy in cancer patients: fact or fiction? Cancer Res 2013;73: 6384-6388.

21 Bernhard H, Neudorfer J, Gebhard K, Conrad H, Hermann C, Nahrig J, Fend F, Weber W, Busch DH, Peschel C: Adoptive transfer of autologous, HER2-specific, cytotoxic $\mathrm{T}$ lymphocytes for the treatment of HER2-overexpressing breast cancer. Cancer Immunol Immunother 2008;57:271-280.

22 Rack B, Juckstock J, Gunthner-Biller M, Andergassen U, Neugebauer J, Hepp P, Schoberth A, Mayr D, Zwingers T, Schindlbeck C, et al.: Trastuzumab clears HER2/neu-positive isolated tumor cells from bone marrow in primary breast cancer patients. Arch Gynecol Obstet 2012;285:485-492.

23 Bozionellou V, Mavroudis D, Perraki M, Papadopoulos S, Apostolaki S, Stathopoulos E, Stathopoulou A, Lianidou E, Georgoulias V: Trastuzumab administration can effectively target chemotherapy-resistant cytokeratin-19 messenger RNA-positive tumor cells in the peripheral blood and bone marrow of patients with breast cancer. Clin Cancer Res 2004;10:8185-8194.

24 Heitzer E, Auer M, Gasch C, Pichler M, Ulz P, Hoffmann EM, Lax S, Waldispuehl-Geigl J, Mauermann O, Lackner C, et al.: Complex tumor genomes inferred from single circulating tumor cells by array-CGH and next-generation sequencing. Cancer Res 2013;73: 2965-2975.

25 Fasching PA, Brucker SY, Fehm TN, Overkamp F, Janni W, Wallwiener M, Hadji P, Belleville E, Haberle L, Taran FA, et al.: Biomarkers in patients with metastatic breast cancer and the PRAEGNANT study network. Geburtshilfe Frauenheilkd 2015;75:41-50.

26 Fehm T, Solomayer EF, Meng S, Tucker T, Lane N, Wang J, Gebauer G: Methods for isolating circulating epithelial cells and criteria for their classification as carcinoma cells. Cytotherapy 2005;7:171-185.

27 Krawczyk N, Meier-Stiegen F, Banys M, Neubauer H, Ruckhaeberle E, Fehm T: Expression of stem cell and epithelial-mesenchymal transition markers in circulating tumor cells of breast cancer patients. Biomed Res Int 2014;2014:415721.

28 Kasimir-Bauer S, Hoffmann O, Wallwiener D, Kimmig R, Fehm T: Expression of stem cell and epithelial-mesenchymal transition markers in primary breast cancer patients with circulating tumor cells. Breast Cancer Res 2012;14:R15.
Schwarzenbach H, Hoon DS, Pantel K: Cell-free nucleic acids as biomarkers in cancer patients. Nat Rev Cancer 2011;11:426-437.

30 Bettegowda C, Sausen M, Leary RJ, Kinde I, Wang Y, Agrawal N, Bartlett BR, Wang H, Luber B, Alani RM, et al.: Detection of circulating tumor DNA in earlyand late-stage human malignancies. Sci Transl Med 2014;6:224ra24.

31 Dawson SJ, Rosenfeld N, Caldas C: Circulating tumor DNA to monitor metastatic breast cancer. N Engl J Med 2013;369:93-94.

32 Rothe F, Laes JF, Lambrechts D, Smeets D, Vincent D, Maetens M, Fumagalli D, Michiels S, Drisis S, Moerman C, et al.: Plasma circulating tumor DNA as an alternative to metastatic biopsies for mutational analysis in breast cancer. Ann Oncol 2014;25:1959-1965.

33 Diaz LA Jr, Bardelli A: Liquid biopsies: genotyping circulating tumor DNA. J Clin Oncol 2014;32:579-586.

34 Spindler KL, Appelt AL, Pallisgaard N, Andersen RF, Brandslund I, Jakobsen A: Cell-free DNA in healthy individuals, noncancerous disease and strong prognostic value in colorectal cancer. Int J Cancer 2014;135: 2984-2991.

35 Singh N, Gupta S, Pandey RM, Chauhan SS, Saraya A: High levels of cell-free circulating nucleic acids in pancreatic cancer are associated with vascular encasement, metastasis and poor survival. Cancer Invest 2015;33: $78-85$.

36 Heidary M, Auer M, Ulz P, Heitzer E, Petru E, Gasch C, Riethdorf S, Mauermann O, Lafer I, Pristauz G, et al.: The dynamic range of circulating tumor DNA in metastatic breast cancer. Breast Cancer Res 2014;16:421.

37 Madic J, Kiialainen A, Bidard FC, Birzele F, Ramey G, Leroy Q, Rio Frio T, Vaucher I, Raynal V, Bernard V, et al.: Circulating tumor DNA and circulating tumor cells in metastatic triple negative breast cancer patients. Int J Cancer 2015;136:2158-2165.

38 Murtaza M, Dawson SJ, Tsui DW, Gale D, Forshew T, Piskorz AM, Parkinson C, Chin SF, Kingsbury Z, Wong AS, et al.: Non-invasive analysis of acquired resistance to cancer therapy by sequencing of plasma DNA. Nature 2013;497:108-112.

39 Sefrioui D, Perdrix A, Sarafan-Vasseur N, Dolfus C, Dujon A, Picquenot JM, Delacour J, Cornic M, Bohers E, Leheurteur M, et al.: Short Report: Monitoring ESR1 mutations by circulating tumor DNA in aromatase inhibitor resistant metastatic breast cancer. Int J Cancer 2015;137:2513-2519.

40 Guttery DS, Page K, Hills A, Woodley L, Marchese SD Rghebi B, Hastings RK, Luo J, Pringle JH, Stebbing J, et al.: Noninvasive detection of activating estrogen receptor 1 (ESR1) mutations in estrogen receptor-positive metastatic breast cancer. Clin Chem 2015;61:974-982.

41 Ma M, Zhu H, Zhang C, Sun X, Gao X, Chen G: 'Liquid biopsy'-ctDNA detection with great potential and challenges. Ann Transl Med 2015;3:235.

42 Rack BK, Schindlbeck C, Andergassen U: Use of circulating tumor cells (CTC) in peripheral blood of breast cancer patients before and after adjuvant chemotherapy to predict risk for relapse: the SUCCESS trial. J Clin Oncol 2010;28(suppl 15):abstr 1003.

43 Smerage JB, Barlow WE, Hortobagyi GN, Winer EP, Leyland-Jones B, Srkalovic G, Tejwani S, Schott AF, O'Rourke MA, Lew DL, et al.: Circulating tumor cells and response to chemotherapy in metastatic breast cancer: SWOG S0500. J Clin Oncol 2014;32:3483-3489.

${ }_{44}$ Bidard FC, Fehm T, Ignatiadis M, Smerage JB, AlixPanabieres C, Janni W, Messina C, Paoletti C, Muller V, Hayes DF, et al.: Clinical application of circulating tumor cells in breast cancer: overview of the current interventional trials. Cancer Metastasis Rev 2013;32:179-188. 